\title{
Author Index Vol. 49, 1997
}

Adkins-Regan, E. 53 Alves-Gomes, J. .324 Anastasio, TJ. 214 Ashwell, K.W.S. 276 Bodznick,D. 99 Carr,J.A. 149 Domes, K.M. 53 Duman, C.H. 99 Faulkes, Z. 162 Femald, R.D. 230 Fortune, E.S. 312 Grubb,T.C.,Jr. 110 Halpem,B.P. 53 HopkiMc.D. 324 Iqbal,J. 261 JacobsomC.D. 261

Jarrard,H.E. 249 Keng,MJ. 214 Kim,Y. 149 Krug,L. 39 Kuehl-Kovarik, M.C. Leger,J.P. 63 Mason, R.T. 137

Mathieson, W.B. 63 Medina, L. 78 Moore, F.L. 137 Northcutt, R.G. 1 Pardue, M.T. 295 pSSJD.H. 162 BM.B. 237 Reiner, A. 78 Riedel, G. 20 , 39 Rose, G. J. 312 Roth, A. 132 Schlegel, P.A. 121,132 Schuett,K.C 110 SivakJ.G. 295 Smith, M.T. 137 Striedter, G.F. 179 Veenman.C.L. 78 Volman.S.F. 110 Wicht,H. 1 Winberg, S. 230 Winberg,Y. 230 Zhang, L.-L. 276 
KARGER

Basel

E. E-Mail 